\title{
Detection of post-fire residuals using high- and medium-resolution satellite imagery ${ }^{1}$
}

\author{
by Mark Kachmar², 3 and G. Arturo Sánchez-Azofeifa², 4
}

\begin{abstract}
Forest fires can burn across large forested areas over short time periods, but they rarely consume all the trees in their path. Fires leave live irregularly shaped patches or rows of mature trees known as "residuals" within the fire perimeter. IKONOS and Landsat Enhanced Thematic Mapper Plus satellite imagery were acquired over two forested areas affected by fire in the northern boreal forest of Alberta. Each image was classified and residuals were detected with greater than $88 \%$ accuracy. Residual patches were grouped into nine minimum mapping unit (MMU) classes and area, patch, and shape level metrics were calculated for each group. Analysis of metric results highlighted how the choice of satellite imagery used to characterize and quantify residuals, the size of the MMU used to define the residuals, and human induced land use cover change (LUCC) processes occurring within fire perimeters were interrelated factors that impacted estimates of residual numbers and sizes. Residual metrics calculated in one fire perimeter should therefore be carefully assessed according to local land use and land cover change dynamics before suggesting that residual information captured in any fire perimeter can typify residual patterns elsewhere.
\end{abstract}

Key words: remote sensing, high resolution, medium resolution, satellite imagery, forest fires, wildfire, residual forest islands, geographic information systems (GIS), minimum mapping unit

\section{RÉSUMÉ}

Les feux de forêt peuvent brûler de grandes superficies forestières en peu de temps, mais ils consument rarement tous les arbres sur leur parcours. Les feux laissent des parcelles de forme irrégulières ou des rangées d'arbres mûrs identifiés comme des « résidus verts » au cœur du périmètre incendié. Des images obtenues par télédétection à partir des systèmes IKONOS et Landsat Enhanced Thematic Mapper Plus ont été sélectionnées dans le cas de deux zones forestières brûlées dans la forêt boréale du nord de l'Alberta. Chaque image a été classifiée et les résidus verts ont été détectés avec une précision de plus de $88 \%$. Les parcelles de résidus verts ont été regroupées sous neuf classes d'unité minimale de cartographie et les données relatives à la superficie, à la parcelle et à la forme de celle-ci ont été calculées pour chaque groupe. L'analyse des données a mis en évidence comment le choix de l'imagerie de télédétection retenue pour caractériser et quantifier les résidus, la taille de l'unité minimale utilisée pour définir les résidus et les processus de changement du type d'utilisation du territoire introduit par l'homme au sein des périmètres brûlés constituaient des facteurs en interaction qui avaient un impact sur les estimés portant sur le nombre et la taille des résidus. Les données sur les résidus calculés pour un périmètre brûlé devraient en conséquence être évaluées avec précaution en fonction de l'utilisation locale du territoire et de la dynamique du changement de cette utilisation avant de suggérer que l'information sur les résidus recueillie dans n’importe quel périmètre brûlé puissent être un exemple des patrons de résidus en d'autres endroits.

Mots clés : télédétection, grande résolution, résolution moyenne, imagerie de télédétection, feux de forêt, faune hors contrôle, îlots de forêts résiduelles, système d'information géographique, unité minimale de cartographie

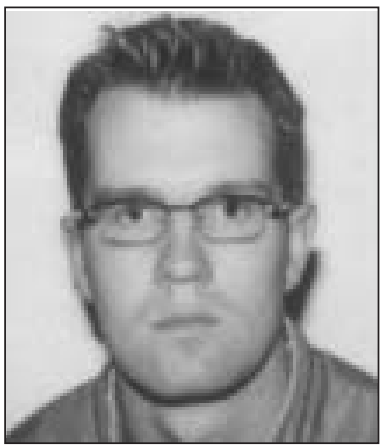

Mark Kachmar

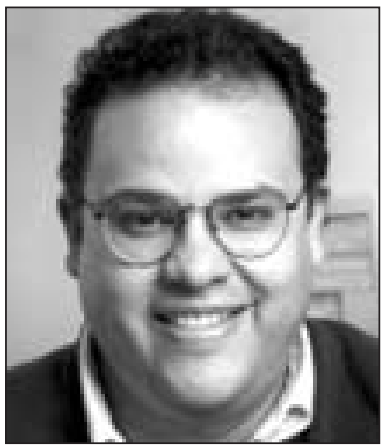

G. Arturo Sánchez-Azofeifa

\section{Introduction}

Each year approximately 5000-12 000 forest fires covering roughly 1-3 million hectares burn across areas of Canada (Amiro et al. 2001). In boreal regions, these fires can affect large areas but fire severity (i.e., the destructive capability of fire to the forest floor and canopy) is not constant across the landscape and is instead modified by local weather, fuel moisture, topography and pre-fire vegetation types at the time of burning (Sousa 1984, Bonan and Shugart 1989). These forest fires rarely consume everything in their path and tend to leave behind live irregularly shaped patches and/or linear rows of mature trees (i.e., residuals) within the fire perimeter (Rowe and Scotter 1973).

\footnotetext{
${ }^{1}$ Presented at "One Forest Under Two Flags," Canadian Institute of Forestry / Institut forestier du Canada and the Society of American Foresters Joint 2004 Annual General Meeting and Convention held October 2-6, 2004, Edmonton, Alberta, Technical Session on Remote Sensing for Forestry.

${ }^{2}$ Earth Observation Systems Laboratory, Department of Earth and Atmospheric Sciences, University of Alberta, Edmonton, Alberta T6G 2 E3.

${ }^{3}$ Current address: ESRI Canada Limited, Suite 200, 9940106 St., Edmonton Alberta T5K 2N2.

${ }^{4}$ Corresponding author. E-mail: arturo.sanchez@ualberta.ca
} 
Residuals are economically and ecologically significant in boreal forest environments. Unburned patches provide legacies of forest structure and may serve as life-boats for species as the surrounding forest regenerates. Previous post-fire research has shown that the proportion of residual patches increases proportionally to the size of the fire perimeter (Eberhart and Woodard 1987) and that residuals may comprise 3\% to $15 \%$ (Delong and Kessler 2000) or up to $40 \%$ (Fraser et al. 2004) of the vegetation cover within fire-affected areas. Identifying and locating post-fire residuals is critical information for foresters conducting post-fire site evaluations (Eberhart and Woodard 1987), for aiding in tree regeneration (Greene et al. 1999), and protecting bird habitat (Schieck and Hobson 2000). Information on the number, size, shape and location of post-fire residuals is also important for forestry companies that use information about residuals to establish guidelines for devising residual-retention forest harvesting practices within their forest management areas. During postfire salvage logging operations, forestry companies can benefit from maps that show the locations and sizes of residual forest patches. Information on the total area of residuals within fire perimeters is also useful for forest fuel mapping (Conard et al. 2001, Sandberg et al. 2001), carbon (Amiro et al. 2001) and fire modelling initiatives (Keane et al. 2001).

Various approaches exist for characterizing land use and land cover types on the earth's surface. Land cover refers to the biophysical attribute of the land surface (i.e., deciduous forest) and land use refers to the human processes that the land is being used for (Nunes and Augé 2003). One method currently used to characterize post-fire land cover by government agencies within the Canadian provinces and the Northwest Territories is to circle a fire site with a helicopter equipped with an onboard global positioning system. From this method, the perimeter of the fire can be defined and large area residual forest stands can be delimited. Alternately, postfire aerial photography can be acquired and used for interpreting residual stands (Amiro and Chen 2003). In the case of large fires (> $100000 \mathrm{ha}$ ) where numerous aerial photographs may be needed, however, manual photo-interpretation can be laborious and the accuracy of analysis affected by the experience of the photo-interpreter (Strand et al. 2002). Medium- and high-resolution satellite imagery can also be used to analyze post forest fire environments (Pereira and Setzer 1993, White et al. 1996). Rather than for classifying post-fire residuals, however, satellite imagery is typically used only to define the fire perimeter (Sunar and Özkan 2001, Bougeau-Chavez et al. 2002) or assess post-fire regeneration (Riaño et al. 2002). Image interpretation methods usually involve processing satellite images that were acquired both prior to and after the fire (Rogan and Yool 2001, Miller and Yool, 2002) or by using normalized difference vegetation index (NDVI) methods (Garcia-Haro et al. 2001).

Various explanations can be provided for the lack of studies using satellite imagery to detect and analyze post-fire residuals. The first is the human context that dictates what information will be represented in the final legend of a map (Harley 1989, Dorling 1998). For instance, if certain residual forest patches are not considered valuable ecologically and/or they are not considered economically relevant for forestry companies, it is likely that these patches will not be present in the legend of a final image classification. Another reason relates to the challenge of acquiring satellite imagery at an opportune time after the fire when it is possible to discriminate between residuals and rapidly growing green understory (Larson 1980, White et al. 1996, Diaz-Delgado et al. 2003).

The main goal of this study was to detect, classify and examine the spatial dynamics of post-fire residuals using data collected from high- and medium-resolution satellite imagery. This study does not focus on identifying tree mortality in post-fire environments using satellite imagery as tree mortality induced by surface fire varies with time and cannot be determined immediately post-fire (Kafka et al. 2001). Rather, the first objective of this study was to classify residuals using unsupervised and supervised classification techniques using satellite imagery at different fire sites. The second objective was to group all forest patches into nine classes and analyze their shape, size and complexity as function of fire site. Finally, residual patch and shape level metrics calculated for each fire affected area were to be discussed relative to 1) the image used to detect residuals, 2) the mapping unit interval chosen to define the residual size, and 3) the local land use and cover change dynamics occurring within each of the fire perimeters.

\section{Study Area and Methods 2001 Chisholm Fire study area}

We examine two fire-affected areas in Northern Alberta, Canada (Fig. 1, 2 and 3). Both the 2001 Chisholm and the 2002 House River fires occurred within the Boreal forest region described by Rowe and Scotter (1973). Strong and Leggat (1981) provide a description of the physiography and climate of the study areas. Elevation ranges from less than 250 $\mathrm{m}$ above sea level in the northeast to $1400 \mathrm{~m}$ in the southwest. Soils consist primarily of grey luvisols. Summer precipitation

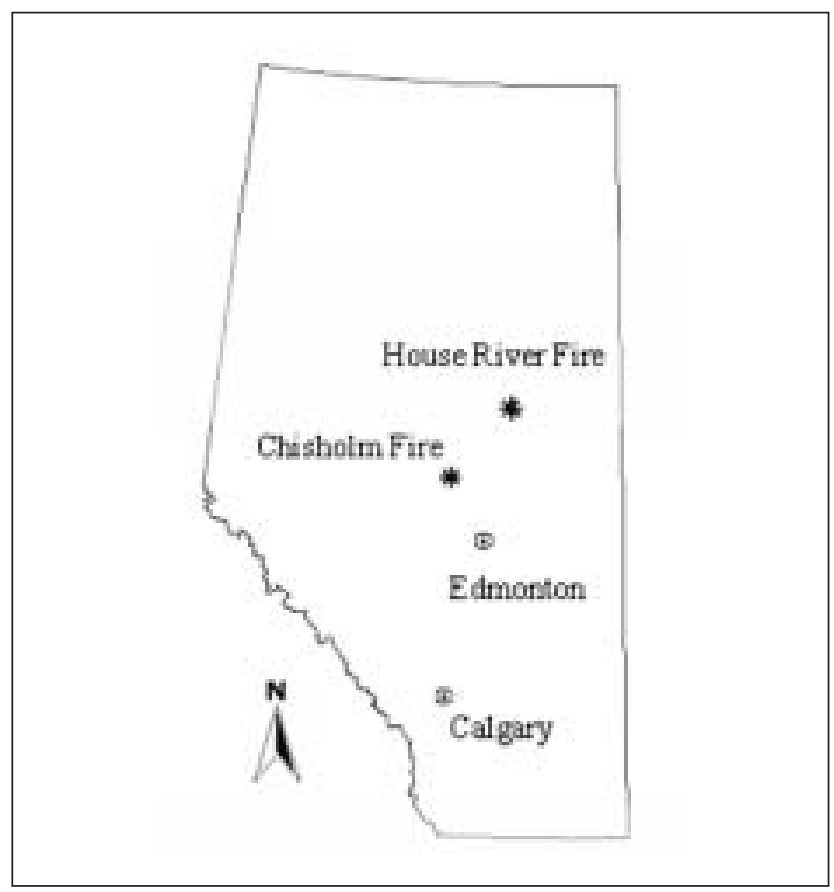

Fig. 1. Location of the Crow Lake Ecological Reserve laffected by the 2002 House River Fire) and the 2001 Chisholm Fire, overlaid onto the border of the Province of Alberta, Canada 


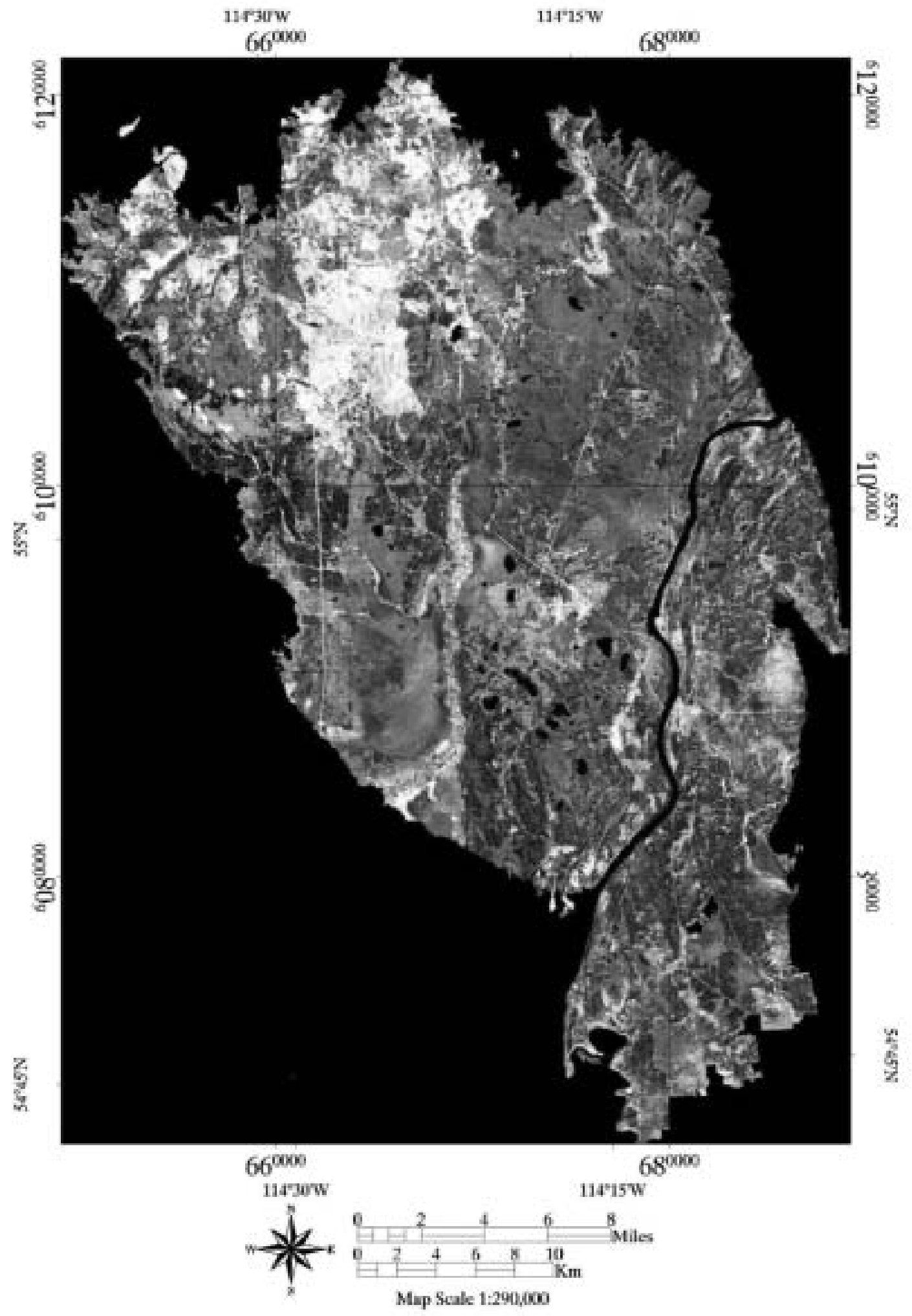

Fig. 2. Outline of the 2001 Chisholm Fire perimeter represented by a Landsat ETM+ image. Darker colors represent those areas burnt in the fire. The Landsat ETM+ image was subset from the original full image scene (Path 43 Row 22) and georectified using an image to vector registration by selecting ground control points at key road intersection using 1: 20000 vector access data. The image was reprojected to Universal Transverse Mercator (UTM) Zone 11, NAD 83 for subsequent processing. access data. The image was reprojected to Universal Transverse Mercator (UTM) Zone 11, NAD 83 for subsequent processing. 


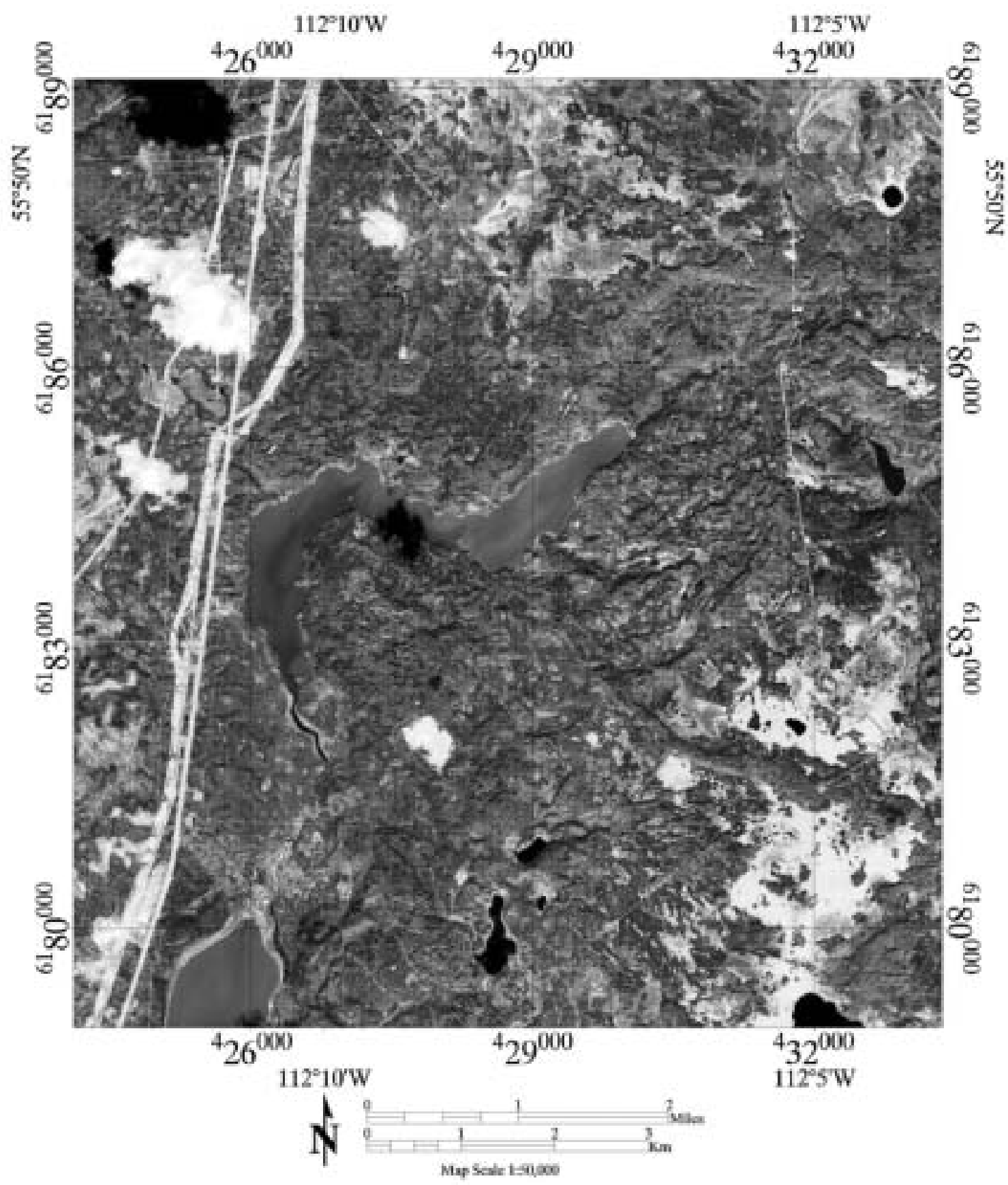

Fig. 3. Panchromatic IKONOS image that was acquired over the House River Fire on August 29, 2002. Burnt regions are represent towards the center of the image. Crow Lake is also located near the centre of the image. For the 2002 House Rive Fire, an IKONOS multispectral+pancromathic image was acquired over a $10 \times 10 \mathrm{~km}$ area (Crow Lake Ecological Reserve). This image was reprojected to UTM Zone 12 and the boundary of the IKONOS scene formed the study area.

(May to September) varies from 180-440 mm with maximum precipitation occurring in July. Dominant tree species found throughout this area include white spruce (Picea glauca (Moench) Voss), black spruce, (Picea mariana (Mill. (BSP)), and trembling aspen (Populus tremuloides Michx.).

The Chisholm fire ignited on May 23, 2001, near the hamlet of Chisholm, Alberta, and was estimated at over 116000 hectares. The forest industry lost 4.5 million cubic metres of growing stock and over 6300 ha of harvesting units (i.e., cutblocks) in varying stages of forest regeneration (Chisholm Fire Review Committee Final Report 2001). The primary image data source for the study of this fire is a cloud-free Landsat Enhanced Thematic Mapper Plus (ETM+) multispectral image (Path 43 Row 22) acquired on 23 September 2001, approximately four months following the fire.

The 2002 House River Fire in Northern Alberta, burned 
over 248000 hectares in May 2002, forcing the evacuation of the communities of Conklin, Sandy Lake, Keg River, Peerless Lake, Trout Lake, Fox Lake and the Sunchild Indian Reserve (Chisholm Fire Review Committee Final Report 2001). A multispectral IKONOS image (4-m resolution) was acquired approximately three months after the fire on August 29, 2002. The area imaged was affected by the 2002 House River fire and is know locally as the Crow Lake Ecological Reserve $\left(112.10^{\circ} \mathrm{W}, 55.78^{\circ} \mathrm{N}\right)$. In this study the IKONOS image acquired over the House River fire is only a small subset of the entire fire affected area. Post-fire IKONOS imagery of the 2001 Chisholm fire was not available for analysis.

\section{Image processing and field data collection}

Preliminary interpretation of the satellite images focused on visually identifying the major land cover types in both images (green residual, burnt areas, wetland and water bodies). To begin grouping the land cover types into classes, each image was pre-processed into fifty spectral clusters using the ISODATA unsupervised classifier (Tou and Gonzalez 1974, Richards 1994). An atmospheric correction was not applied to the satellite images as each scene was processed and classified independently (Song et al. 2001). The fifty spectral classes were then grouped into classes that included non-target (lakes, clouds, cloud shadows, haze, fire-affected areas, gravel pits, wetland areas) and target classes (residual areas). These image processing operations resulted in a preliminary classified map that could be taken into the field and used to select training sites.

A ground-truthing field campaign was conducted during summer 2002 (June-July-August) to identify green residual areas, to document major land cover types and to identify spurious features within the study areas (Sánchez-Azofeifa et al. 2003). To support improved in-field residual identification, both satellite images were printed at a 1:50 000 scale and overlaid with 1:20 000 scale vector access data (road, transmission lines, and hydrological vectors). In the field, residual training sites were located using the maps and residual locations were recorded with a GPS. For the 2001 Chisholm fire, 65 validation areas were collected throughout the study area. In the 2002 House River fire study, 98 validation areas were collected. As salvage logging operations were occurring before, during and following the field campaign in the Chisholm Fire area, validation information can only be verified for those residual areas observed during the field campaign.

\section{Residual forest classification and metric generation}

Following the field data collection phase, image processing involved removing non-target features from the images, including water bodies, clouds and cloud shadows. The resulting images contained only land cover types. Using known residual locations observed on the field maps, a minimum of 500 spectrally distinct image pixels ( 40 ha Chisholm Fire/0.8 ha House River fire) representing residual forest were selected for supervised image classification. These training areas were input into a maximum likelihood supervised classifier using the visible and near-infrared image bands to derive an output classified image (Richards 1994). The resulting residual-forest only layer was then filtered using a $3 \times 3$ median filter to reduce noise in the image (Zukowskyj et al. 2001). Non-target land cover types were masked out of this layer, resulting in a residual only map.
Classified residual forest patches were converted from raster to polygons and grouped into nine size classes (ranging from 0.1 ha to greater than $80 \mathrm{ha}$ ). For each residual area class, we calculated residual class area (CA), number of residual patches (NumP) and mean residual patch size (MPS) (McGarigal and Marks 1994). Considering that residual patch shapes can be modified by the presence of linear features (i.e., roads) within the study areas, we calculated residual shapes complexity using the areal weighted mean shape index (AWMSI). AWMSI is a robust method used to measure the average patch shape or the average perimeter-to-area ratio for the residuals and can highlight patches that tend to from circular shapes or instead occur as jagged patterns with rough edges (Saura 2002). This information is important, considering that fire-affected areas do not always have clear transitions between deciduous and coniferous forest stands, or these stands can be modified by the presence and locations of linear features (i.e., roads) (Fig. 8).

\section{Results}

Residual classification and patch and shape level metrics

Each of the study areas occurs in different geographic areas undergoing different land use and land cover processes. The area within the 2001 Chisholm fire is affected by oil/gas activity and forest harvesting operations, whereas the study area for the 2002 House River Fire is an ecological reserve. Residual forest classification accuracy is presented for both study areas based on validation areas that were captured during the 2002 field seasons. For the 2001 Chisholm fire, 57 out of 65 residual validation areas were correctly classified as residual forest. Residual forest classification accuracy for the 2001 Chisholm fire was $88 \%$. Although the accuracy is high, image classification accuracy did vary slightly depending on the location of the residuals within the study area. Typically, residuals were classified with the highest accuracy in those portions of the Chisholm fire site where residual patches maintained bona-fide physical boundaries and clearly defined spectral separability between fire affected and residual areas. Confusion in spectral separability existed primarily between the newly regenerating forest harvesting cutblocks in the northern portion of the study and live residual forest in other locations. This confusion resulted in a decrease in the ability to accurately classify the residuals from other nonburnt regenerating forest within the cutblocks. As no industrial activity and forest harvesting operations were occurring in the Crow Lake Ecological Reserve, the residual forest classification map received a slightly higher classification accuracy of $94 \%$ with 92 out of 98 residual forest validation areas being classified correctly.

Total residual forest area was calculated for both fires to assess the percentage of standing live residual. Thirty-three percent of land cover within the boundary of the 2001 Chisholm fire was classified as residual forest. Given that the residuals maintained different sizes and shapes within the Chisholm fire perimeter, detailed patch and shape level metrics are examined across the nine MMUs. Patch and shape level metric results are shown in Table 1. Field observations highlighted that residuals exist in many shapes and forms through the fire perimeter (Fig. 8). Residuals could form large homogenous stands surrounded by a larger completely burnt area or they could occur along the edge of a linear feature such as a road, transmission or seismic line. 
Table 1. Residual forest patch metrics as a function of residual mapping unit for the 2001 Chisholm Fire derived from a supervised maximum likelihood classification on a 28.5-m resolution Landsat ETM+ image

\begin{tabular}{lccccccccc}
\hline Metrics & $<\mathbf{0 . 1}$ & $\mathbf{0 . 1 1 - 1}$ & $\mathbf{1 . 1 - 5}$ & $\mathbf{5 . 1 - 1 0}$ & $\mathbf{1 0 . 1 - 2 0}$ & $\mathbf{2 0 . 1 - 4 0}$ & $\mathbf{4 0 . 1 - 6 0}$ & $\mathbf{6 0 . 1 - 8 0}$ & $>\mathbf{8 0}$ \\
\hline Class Area (ha) & 423.2 & 1887.9 & 2790.5 & 1594.0 & 1669.8 & 1828.4 & 840.7 & 679.3 & 26116.9 \\
Number Patches & 6771 & 5278 & 1244 & 224 & 117 & 66 & 17 & 10 & 51 \\
Mean Patch Size (ha) & 0.06 & 0.4 & 2.2 & 7.1 & 14.3 & 27.7 & 49.5 & 67.9 & 512.1 \\
AWMSI $^{1}$ & 3.4 & 22.8 & 133.6 & 192.3 & 255.5 & 232.7 & 90.8 & 55.4 & 511.9 \\
\hline
\end{tabular}

${ }^{1}$ Areal weighted Mean Shape Index (AWMSI)

Table 2. Residual forest patch metrics as a function of residual mapping unit for the 2002 House River Fire derived from a supervised maximum likelihood classification on a 4-m resolution IKONOS image

\begin{tabular}{lccccccccc}
\hline Metrics & $<0.1$ & $\mathbf{0 . 1 1 - 1}$ & $\mathbf{1 . 1 - 5}$ & $\mathbf{5 . 1 - 1 0}$ & $\mathbf{1 0 . 1 - 2 0}$ & $\mathbf{2 0 . 1 - 4 0}$ & $\mathbf{4 0 . 1 - 6 0}$ & $\mathbf{6 0 . 1 - 8 0}$ & $>\mathbf{8 0}$ \\
\hline Class Area (ha) & 190.8 & 263.6 & 218.8 & 74.2 & 50.9 & 155.5 & 155.7 & 61.0 & 1643.9 \\
Number Patches & 18844.0 & 835.0 & 103.0 & 11.0 & 4.0 & 5.0 & 3.0 & 1.0 & 4.0 \\
Mean Patch Size (ha) & 0.01 & 0.3 & 2.1 & 6.8 & 12.7 & 31.1 & 51.9 & 61 & 411 \\
AWMSI $^{1}$ & 131.0 & 1079.8 & 469.1 & 82.4 & 32.5 & 61.3 & 34.5 & 9.5 & 75.6 \\
\hline
\end{tabular}

${ }^{1}$ Areal weighted Mean Shape Index (AWMSI)

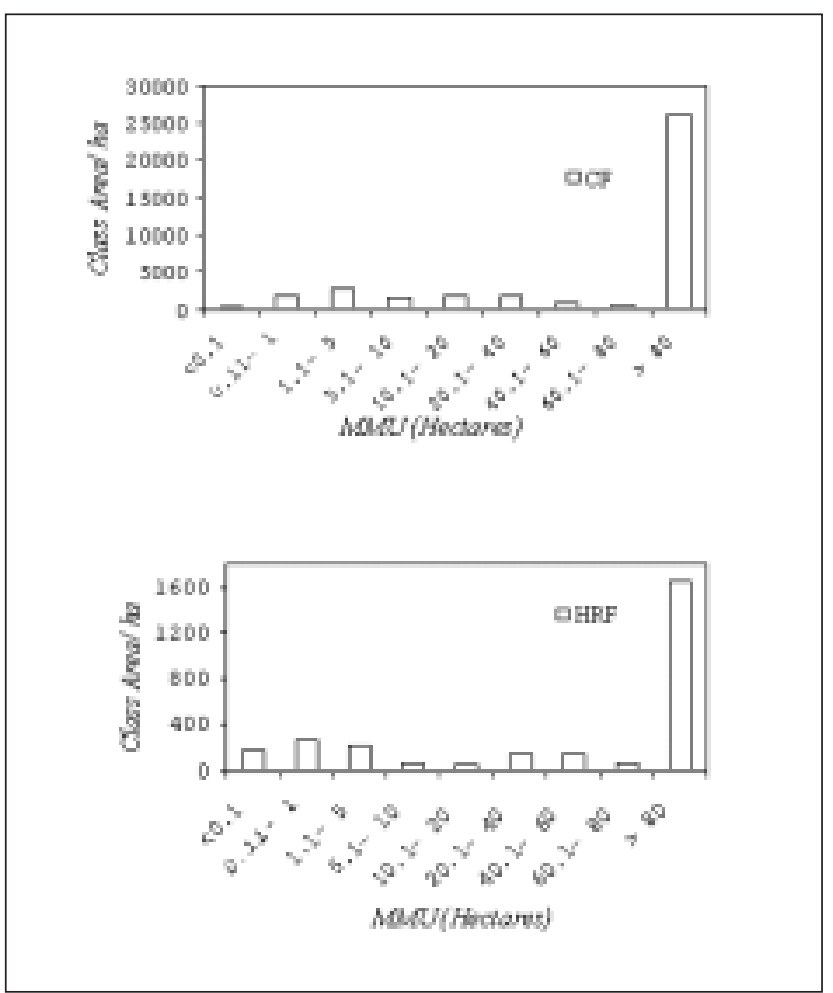

Fig. 4. Total area of the residual forest classes across a range of residual mapping units as derived from a classified Landsat ETM+ image acquired over the perimeter of the 2001 Chisholm fire and from a classified IKONOS image acquired over the 2002 House River Fire.

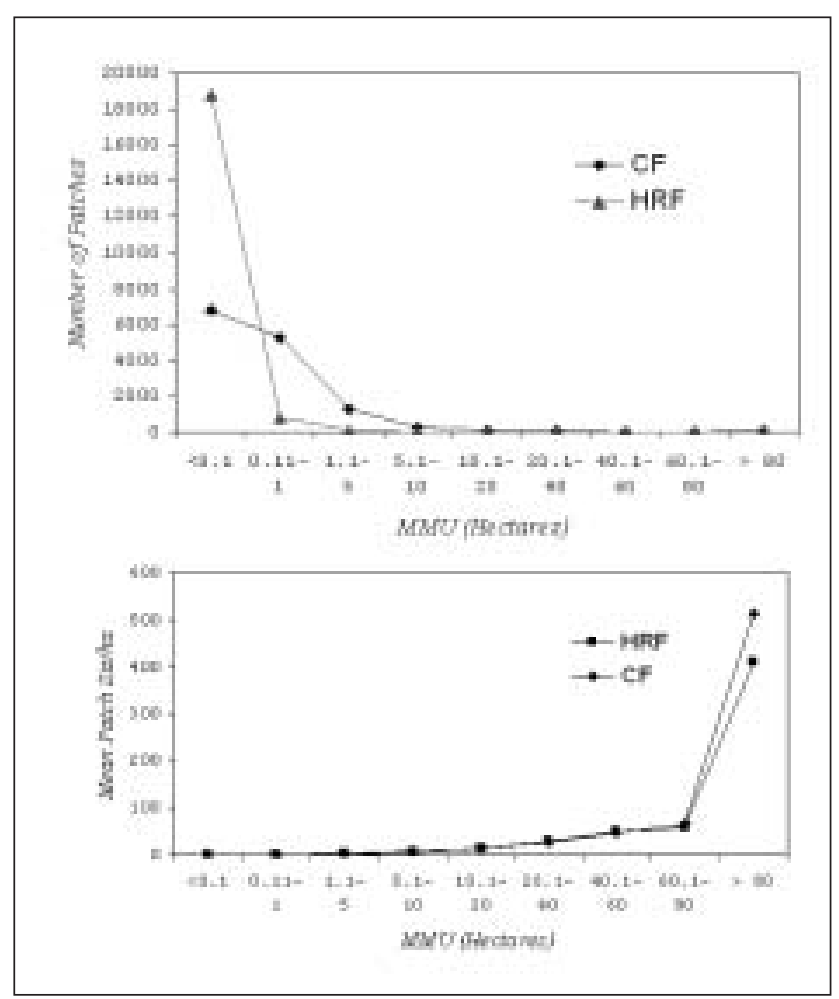

Fig. 5. Number of Patches and Mean Patch Size calculated as a function of residual mapping unit for the perimeter of the 2001 Chisholm and 2002 House River Fires. 


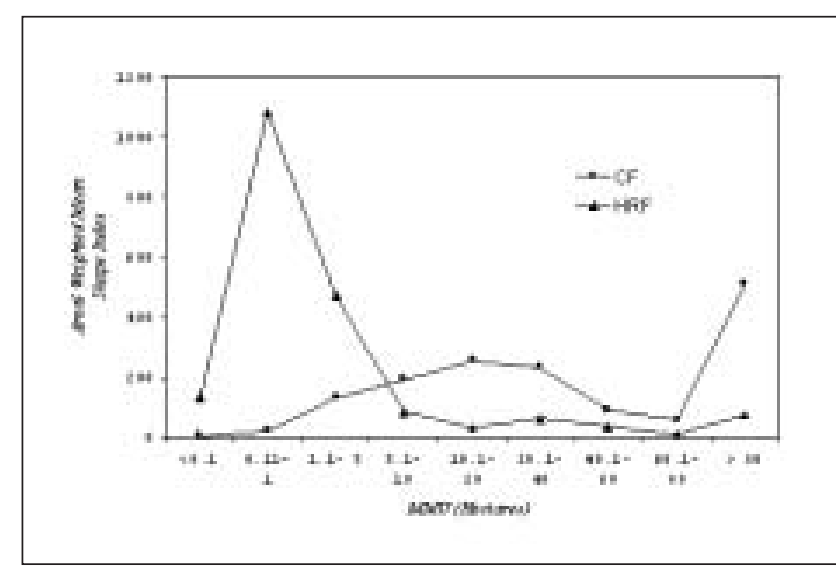

Fig. 6. Areal weighted mean shape index calculated as a function of residual mapping unit for the perimeter of the 2001 Chisholm and 2002 House River fires. AWMSI equals the sum, across all patches, of each patch perimeter $(\mathrm{m})$ divided by the square root of patch area (m2), adjusted by a constant to adjust for a circular standard (vector) or square standard (raster), multiplied by the patch area (m2) divided by total landscape area. In other words, AWMSI equals the average shape index (SHAPE) of patches, weighted by patch area so that larger patches weigh more than smaller ones.

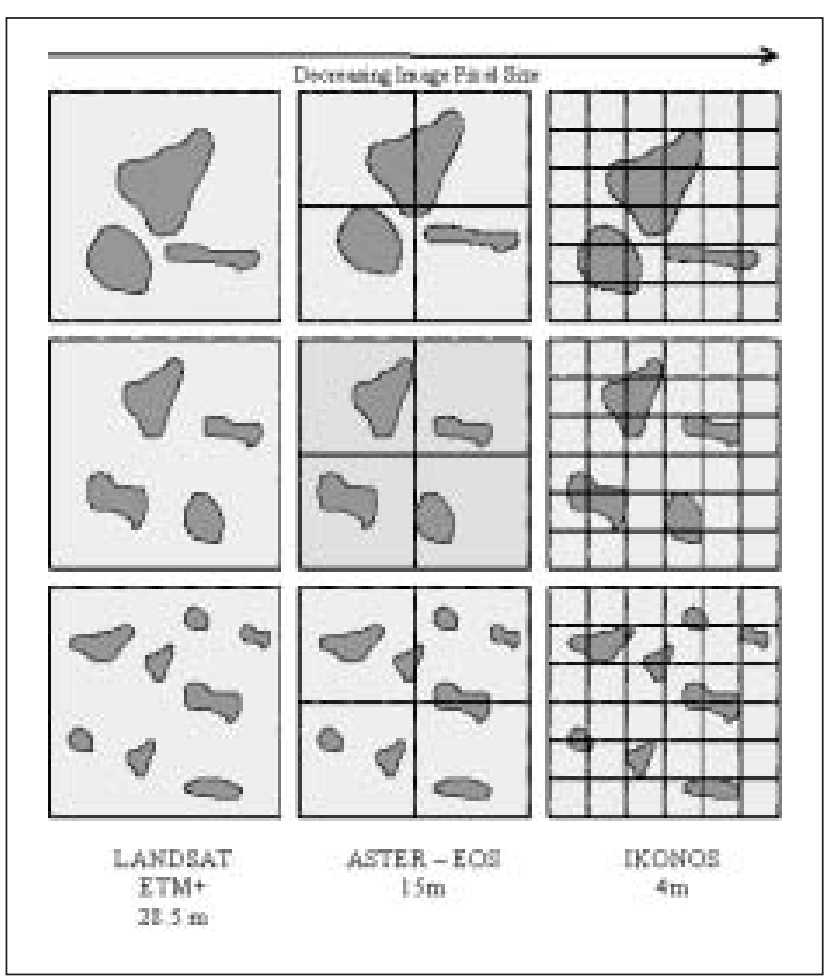

Fig. 7. Bird's eye view of the effect of increasing sensor spatial resolution on different sized residual forest patches overlaid onto a grid representing sensor field of view at arbitrary 28.5-, 15and 4-meter sensor spatial resolution.

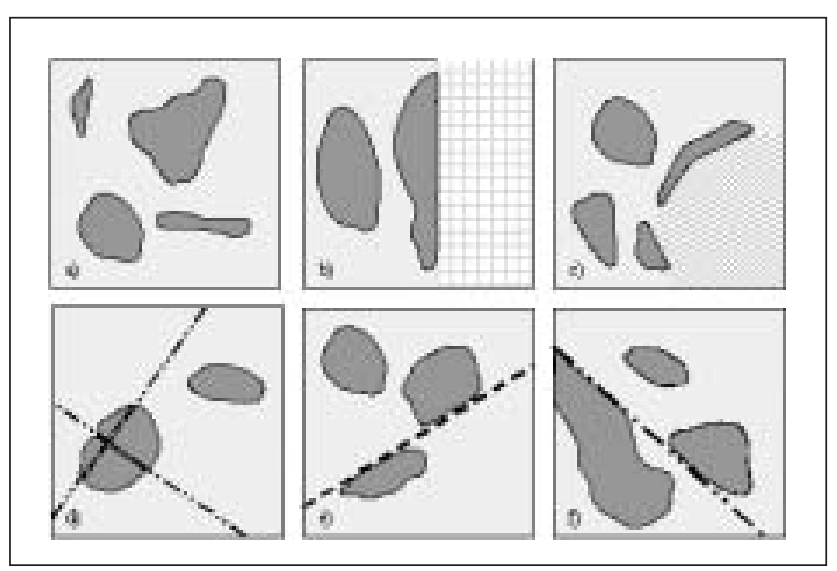

Fig. 8. Bird's-eye-view pictorial representation of the locations and geometric shapes of unburned (residual) forest patches located within the Chisholm (2001) and House River (2002) fire perimeter occurring as a) isolated forest islands; b) between agricultural fields; c) bordering lakes; d) along seismic lines; e] along road edges; and f) along transmission lines.

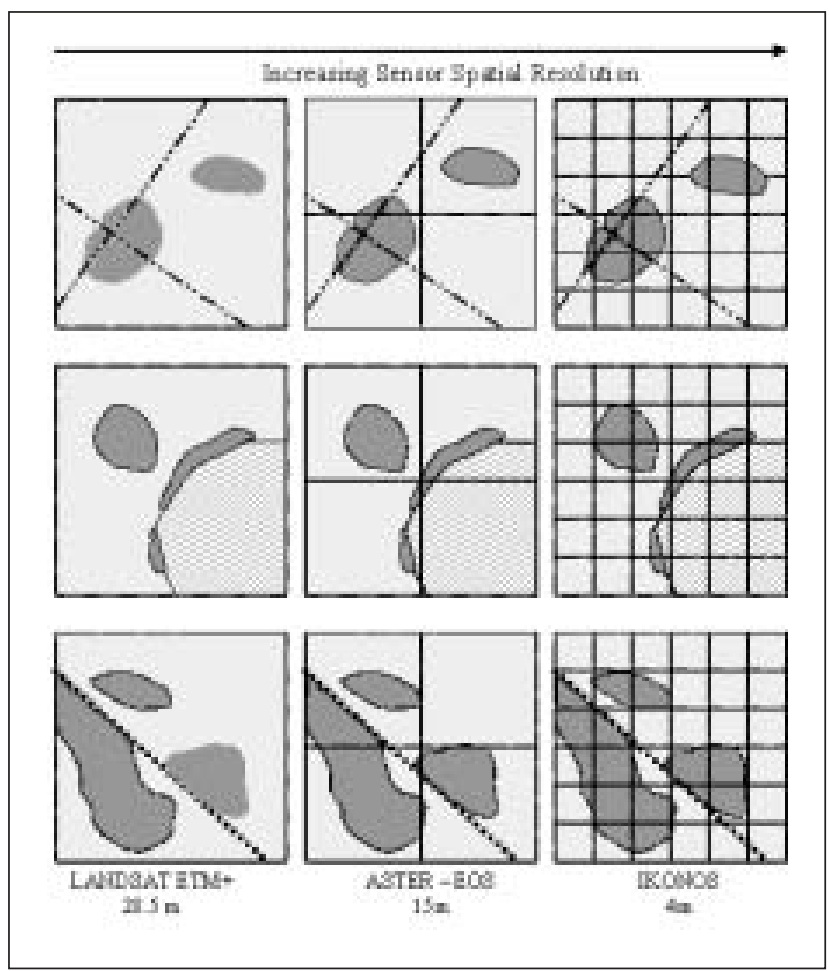

Fig. 9. Pictorial representation of the effect of increasing sensor spatial resolution on different sized residual forest patches affected by a) seismic lines; b) bordering lakes; and c) roads overlaid onto a grid representing sensor field of view at 28.5-, 15- and 4-metre sensor spatial resolution perimeter. 
Within the Chisholm fire perimeter, large-sized residual forest patches dominated the landscape. The largest MMU class (greater than $80 \mathrm{ha}$ ) consisted of a relatively small number of patches. The largest sized class contained only 51 patches while the smallest residual area class $(<0.1 \mathrm{ha})$ reached as high as 6771 patches (Fig. 5). Although the patch size data show a range of residual patches across MMU, the physical context of the residuals must also be considered related to the Landsat imagery used to identify them. For example, many small area patches observed in the field tended to be clumped together during image classification, subsequently being classified and grouped into a single congruent patch. The grouping and clumping of residual patches led to a situation where a large number of small patches fell into the medium-sized MMU classes. Residual patch clumping impacts estimates of residual size as well as the AWMSI. Within the Chisholm Fire the AWMSI tends to highlight a landscape where larger-sized residual area patches have more complex shapes while smaller sized residual patches tended instead to be rounder and less complex (Fig. 6).

Total residual forest area was calculated for the 2002 House River Fire to assess the percentage of standing live residual. Within the fire perimeter of the Crow Lake Ecological Reserve, residual forest area was calculated as 27\%. Table 2 shows an analysis of the residual patches across MMU. Patch level data for the House River fire shows that very many small-sized residual patches ( $<0.1$ ha) occur within this fire site. The smallest MMU class contains 18844 patches (Table 2) in comparison to the largest MMU class (> 80 ha) which contains only four residual patches. Even though the smallest class contains the highest number of patches, the biggest MMU class containing only four patches, encompassed the majority of residual forest area (Fig. 4). Results of the AWMSI highlight increasing complex-shaped, small-area patches, which were visually observed in both the field and the images. The larger-sized residual area classes demonstrate the opposite effect, tending instead to form less complex more circular patches (Fig. 6).

\section{Discussion}

When classifying post-fire residuals using satellite imagery, the physical shape and size of the residuals on the ground should be considered as a factor affecting the accuracy of residual detection. The effect of ground target size and imaging sensor spatial resolution has previously been defined as the optimal spatial resolution whereby object size meets sensor spatial resolution (Woodcock and Strahler 1987, Marceau and Hay 1999). In both study areas, satellite imagery was used to detect post-fire residuals, but yet many residuals occurred as small or irregular-shaped patches. Analysis of residual metrics may therefore vary significantly depending on how the spatial arrangements of the patches within the landscape were optimized to the sensor pixel resolution (Fig. 7). The choice of satellite imagery used to classify and analyze residuals can implicitly exclude certain-size residuals from being detected or when clumping occurs, bias estimates of the residual patches toward larger-sized MMU classes. In the Chisholm fire site, many of the small-sized residuals noted during the field campaigns formed larger-sized patches during image classification, meaning that the patch results typically overestimated the residual patches in the medium- to large-sized residual classes.
Classified residuals were also investigated in terms of residual patch numbers and sizes across a range of MMUs. Even though a standardized MMU (i.e., 5 ha or between a range 1-5 ha) may seem suitable for comparing residual metrics in different areas, residual patch information captured from satellite imagery was affected by sensor resolution, meaning that the information cannot be compared directly. Coarser-resolution imagery may inadvertently lead to lower estimates of the number of small-size residual patches as small residuals may become clumped into larger classes. Although forest ecologists often relate residual sizes and shapes to fire severity, successional processes, and natural obstructions (i.e., lakes), the configurations of residuals may also be related to the locations of roads, highways and other linear feature disturbances that may occur within fire perimeters (Fig. 8 and 9). The process of defining what actually constitutes a forest patch can sometimes become a matter of debate (Bennet 2001). As residual patch size and number of patches within a fire perimeter was affected by the satellite imagery used and landscape conditions, study results could not be compared directly using a "standard-sized mapping unit." The information content that is derived depends on the images employed. Residual data comparisons are also problematic when examining data derived from satellite imagery and other methods such as aerial photography and groundbased studies of residuals. Previous post-fire residual studies using aerial photography such as Eberhart and Woodard (1987) define residual forest patches as unburned patches at least 1 ha in size, while Delong and Kessler (2000) conducted field studies that defined residuals as older forest patches $\leq 10$ ha in size. Even when employing a standardized MMU, satellite image-based studies cannot be compared directly with ground- or field-based studies. A set MMU unit will capture different information depending on the sensor used and the amount of clumping that occurs between residual patches during image classification.

The age, structure, composition, and spatial patterns of forest cover change naturally as a forest grows and develops. Across space and time, the locations, distributions and patterns of residuals also change due to anthropogenic forces and industrial activity occurring in the forest. It is therefore difficult to establish a baseline and to provide general guidelines as to what would be the natural residual patterns on the landscape. Although increased numbers of investigations of the number and size of residual forest patches in fire-affected areas may improve by investigating post-fire residuals in many jurisdictions, the most crucial point is that residual data collected via satellite imagery must be analyzed in scope of the pre-existing landscape conditions in the geographic area where the data were collected.

The ability to quickly acquire satellite imagery post-fire may be a critical benefit for identifying post-fire residuals and using such information to aid in planning post-fire salvage harvesting operation as forestry companies typically have a short post-fire window of opportunity to plan timber harvesting. When using such information over the longer term as a guideline for natural disturbance emulation forest harvesting, forestry personnel should be aware of how the source of the data (i.e., satellite imagery), choice of mapping unit used and pre-existing landscape conditions in an area prior to the fire impact estimates of residual numbers, shapes and sizes. 


\section{Conclusions}

In this study a hybrid unsupervised masking and supervised image classification technique using medium- and/or highresolution satellite imagery was used to detect and examine post-fire residuals occurring within fire perimeters with $>$ $88 \%$ classification accuracy. The results illustrated that both image data sources could be used to identify and classify residuals and both images are suitable for quantifying the total amount of residual forest left standing within a fire perimeter.

In the case of using data on post-fire residuals for detailed residual patch analysis or as a guideline to govern natural disturbance emulation forestry, residual patch and shape level metrics must be considered relative to the sensor used, landscape dynamics occurring in the region, and choice of MMU. Although this study suggests that residual data generated from satellite imagery can be used for general residual mapping and can provide a relatively effective method for estimating the total amount of residual vs. burnt vegetation, using residual data generated from satellite remote sensing as a guideline for emulating forest harvesting should be interpreted cautiously. Any combination of these three major factors reduces the comparability of estimates of residual patch shapes and sizes captured in different geographic areas.

\section{Acknowledgements}

We thank the generous support of the National Network of Centers of Excellence, Sustainable Forest Management (NCESFMN). We thank also the comments of two anonymous reviewers who provided constructive critiques that improved the quality of the document. We also thank Mr. Kenneth Dutchak and Mr. Robert Sleep from Alberta's Forest Protection Division and Mr. Tony Sani from SpatialGeolink for their support to conduct this research.

\section{References}

Amiro, B.D., B.J. Stocks, M.E. Alexander, M.D. Flannigan and B.M. Wotton. 2001. Fire, climate change, carbon and fuel management in the Canadian boreal forest. Int. J. Wildland Fire 10: 405-413.

Amiro, B.D. and J.M. Chen. 2003. Forest fire scar aging using spotvegetation for Canadian ecoregions. Can. J. For. Res. 33: 1116-1125. Bennet, B. 2001. What is a Forest? On the Vagueness of Certain Geographical Concepts. Topoi 20: 189-201.

Bonan, G.H. and H.H. Shugart. 1989. Environmental Factors and Ecological Processes in Boreal Forests. Annual Review of Ecology and Systematics 20: 1-28.

Bougeau-Chavez, L.L., E.S. Kasischke, S. Brunzell, J.P. Mudd and M. Tukman. 2002. Mapping fire scars in global boreal forest using imaging radar data. Int. J. Rem. Sens. 23(20): 4211-4234.

Chisholm Fire Review Committee Final Report. 2001. Alberta Sustainable Resource Development. 53pp. Available from http://www3.gov.ab.ca/srd/forests/chisholm/ [updated 02 November 2001; cited 07 September 2003].

Conard, S.G., T. Hartzell, M.W. Hillbruner and G.T. Zimmerman. 2001. Changing fuel management strategies-The challenge of meeting new information and analysis needs. Int. J. Wildland Fire 10: 267-275.

Delong, S. and W. Kessler. 2000. Ecological characteristics of mature forest remnants left by wildfire. For. Ecol. Manage. 131: 93-106.

Diaz-Delgado, R., F. Lloret X. and Pons. 2003. Influence of fire severity on plant regeneration by means of remote sensing imagery. Int. J. Rem. Sens. 24(8): 1751-1763.

Dorling, D. 1998. Human Cartography: when it is good to map. Environment and Planning A 30: 277-288.
Eberhart, K.E. and P.M. Woodard. 1987. Distribution of residual vegetation associated with large fires in Alberta. Can. J. For. Res. 17: 1207-1212.

Fraser, R.H., R.J. Hall, R. Landry, T. Lynham, D. Raymond, B. Lee and Z. Li. 2004. Validation and Calibration of Canada-Wide CoarseResolution Satellite Burned-Area Maps. Photogrammetric Engineering and Remote Sensing 70(4): 451-460.

Garcia-Haro, F., M.A. Gilabert and J. Melia. 2001. Monitoring fireaffected areas using Thematic Mapper data. Int. J. Rem. Sens. 22(4): 533-549.

Greene, D.F., J.C. Zasada, L. Sirois, D. Kneeshaw, H. Morin, I. Charron and M. Simard. 1999. A review of the regeneration dynamics of North American boreal forest tree species. Can. J. For. Res. 29: 824-839.

Harley, J.B. 1989. Deconstructing the map. Cartographica 26(2): 1-20. Kafka, V., S. Gauthier and Y. Bergeron. 2001. Fire impacts and crowning in the boreal forest: study of a large wildfire in western Québec. Int. J. Wildland Fire 10: 119-127.

Keane, R.E., R. Burgan and J. van Wagtendonk. 2001. Mapping wildland fuels for fire management across multiple scales: Integrating remote sensing, GIS, and biophysical modelling. Int. J. Wildland Fire 10: 301-319.

Larson, J.A. 1980. The Boreal Ecosystem. Academic Press, New York. $500 \mathrm{p}$.

Marceau, D.J. and G.J. Hay. 1999. Remote sensing contributions to the scale issue. Can. J. Rem. Sens. 25(4): 357-366.

McGarigal, K. and B. Marks. 1994. FRAGSTATS ${ }^{\star}$ ARC: Spatial pattern analysis program for quantifying landscape structure (Version 2.0). Corvallis, OR.

Miller, J. and S. Yool. 2002. Mapping forest post-fire canopy consumption in several overstory types using Landsat TM and ETM+ data. Rem. Sens. Env. 82: 481-496.

Nunes, C. and J.I. Augé. (eds.). 1999. Land-Use and Land-Cover Change (LUCC) Implementation Strategy. LUCC Report Series 48. IGBP Secretariat, Stockholm. 125p.

Pereira, M.C. and A.W. Setzer. 1993. Spectral characteristics of fire scars in Landsat 5 TM images of Amazonia. Int. J. Rem. Sens. 14(11): 2061-2078.

Riaño, D., E. Chuvieco, S. Ustin, R. Zomer, P. Dennison, D. Roberts and J. Salas. 2002. Assessment of vegetation regeneration after fire through multitemporal analysis of AVIRIS images in the Santa Monica Mountains. Rem. Sens. Env. 79: 60-71.

Richards, J.A. 1994. Remote sensing digital image analysis. SpringerVerlag, Berlin. 281 p.

Rogan, J. and S.R. Yool. 2001. Mapping fire-induced vegetation depletion in the Peloncillo Mountains, Arizona and New Mexico. Int. J. Rem. Sens. 22(16): 3101-3121.

Rowe, J. and G. Scotter. 1973. Fire in the Boreal Forest. Quaternary Research 3: 444-464.

Sánchez-Azofeifa, G.A., M. Kachmar, M. Kalácska and S. Hamilton. 2003. Experiences in Field Data Collection for Land Use and Land Cover Change Classification in Boreal and Tropical Environments. In Methods for Remote Sensing of Forests: Concepts and Case Studies. pp. 433-446. Kluwer Academic Publishing.

Sandberg, D.V., R.D. Ottmar and G.H. Cushon. 2001. Characterizing fuels in the $21^{\text {st }}$ century. Int. J. Wildland Fire 10: 381-387.

Saura, S. 2002. Effects of minimum mapping unit on land cover data spatial configuration and composition. Int. J. Rem. Sens. 23(22): $4853-4880$.

Schieck, J. and K.A. Hobson. 2000. Bird communities associated with live residual tree patches within cut blocks and burned habitat in mixedwood boreal forests. Can. J. For. Res. 30: 1281-1295.

Song, C., C. Woodcock, K. Seto, M. Lenney and S. Macomber. 2001. Classification and change detection using Landsat TM data: When and how to correct atmospheric effects? Rem. Sens. Env. 75(2): 230-244. 
Sousa, W.P. 1984. The Role of Disturbance in Natural Communities. Annual Review of Ecology and Systematics 15: 353-391.

Strand, G.H., W. Dramstad and G. Engan. 2002. The effect of field experience on the accuracy of identifying land cover types in aerial photographs. Int. J. Applied Earth Observation and Geoinformation 4: 137-146.

Strong, W.L. and K.R. Leggat. 1981. Ecoregions of Alberta. Alberta Forestry, Lands and Wildlife. Edmonton, Alberta.

Sunar, F. and C. Özkan. 2001. Forest fire analysis with remote sensing data. Int. J. Rem. Sens. 22(12): 2265-2277.

Tou, J.T. and R.C. Gonzalez. 1974. Pattern Recognition Principles. Addison-Wesley Publishing Company. 377 p.
White, J.D., K.C. Ryan, C.C. Key and S.W. Running. 1996. Remote Sensing of Forest Fire Severity and Vegetation Recovery. Int. J. Wildland Fire 6(3): 125-136.

Woodcock, C.E. and A.H. Strahler. 1987. The Factor of Scale in Remote Sensing. Rem. Sens. Env. 21: 311-322.

Zukowskyj, P.M., M.A. Bussell, C. Power and R.W. Teeuw. 2001. Quantitative accuracy assessment of contextually filtered classified images. Int. J. Rem. Sens. 22(16): 3203-3222. 